\title{
Crustal structure beneath Tierra del Fuego, Argentina, inferred from seismic P-wave receiver functions and ambient noise autocorrelations
}

\author{
Carolina Buffoni $^{\mathrm{a}, *}$, Martin Schimmel ${ }^{\mathrm{b}}$, Nora Cristina Sabbione ${ }^{\mathrm{a}}$, María Laura Rosa ${ }^{\mathrm{a}}$, Gerardo Connon ${ }^{\mathrm{c}, \mathrm{d}}$ \\ ${ }^{a}$ Departamento de Sismología e Inf. Meteorológica, Facultad de Ciencias Astronómicas y Geofísicas (FCAG), Universidad Nacional de La Plata (UNLP), Paseo del Bosque s/n B1900FWA, \\ Argentina \\ ${ }^{\mathrm{b}}$ Instituto de Ciencias de la Tierra Jaume Almera, Consejo Superior de Investigaciones Científicas (CSIC), Lluis Solé Sabarís s/n, Barcelona E-08028, Spain \\ ${ }^{c}$ Estación Astronómica de Río Grande (EARG), Ruta C y acceso aeropuerto, 9420EAR Río Grande, Argentina \\ d Consejo Nacional de Investigaciones Científicas (CONICET), Av. Rivadavia 1917, C1033AAJ Buenos Aires, Argentina
}

\section{A R T I C L E I N F O}

\section{Keywords:}

Receiver functions

Crustal thickness

$\mathrm{Vp} /$ Vs ratio

Ambient seismic noise autocorrelation

Tierra del Fuego

\begin{abstract}
A B S T R A C T
We investigate the structure of the crust beneath the main island of Tierra del Fuego through a teleseismic receiver function analysis and ambient seismic noise autocorrelation using data of four available broad-band stations. The area is situated in a remote region of southern Argentina where the interaction between the South American and Scotia plates define the Magallanes-Fagnano Fault System. Crustal thickness, Vp/Vs ratios and S-wave velocity models were estimated using the H-k stacking method and the inversion of receiver functions with the Neighbourhood Algorithm. Furthermore, we applied an ambient seismic noise autocorrelation procedure to identify PmP Moho reflections at all stations. The three methods provide consistent estimates for the crustal thickness which ranges from about $24.5 \mathrm{~km}$ in the northern part of the Island to about $39.2 \mathrm{~km}$ in the south. The lowest and highest values of S-wave velocity found, in the most superficial layers of the crust, correlate with the presence of Tertiary and upper Cretacic sediments in the north and with older geological units composed by more consolidated lithologies in the south, respectively. Despite the diverse geological and tectonic settings present, our results do not change significantly for different parameters or subsidiary data sets, i.e., showing the robustness of our models which likely represent closely the local structure beneath the Island. This area is considered a very seismically active one and its crustal structure has been little explored demonstrating the importance of having new models and the necessity to increase the station coverage to allow a more detailed study of the region. Furthermore, the models presented here provide better constraints on the crustal structure, and will facilitate studies of the regional seismicity that can improve our understanding of the seismic hazard posed by earthquakes such as the magnitude 7.5 and 7.8 events that occurred in 1949 .
\end{abstract}

\section{Introduction}

The main island of Tierra del Fuego (TdF) is situated in the southern part of South America, where the transform tectonic boundary between the South American and Scotia plates divides the Island into two continental blocks (Fig. 1). This boundary is represented by a mainly strike-slip lineament known as Magallanes-Fagnano Fault System (MFFS). Even though the main fault of the MFFS has a sinistral displacement, the system is composed of many splays and diverse sub parallel faults that overprint the fold-and-thrust belt and are responsible for the complex tectonic setting that has TdF.
In 1993 geodetic observations started in order to determine the relative movement across the MFFS. First results showed velocities of $5 \mathrm{~mm} /$ year (Del Cogliano et al., 2000) and $6.6 \pm 1.3 \mathrm{~mm}$ /year (Smalley et al., 2003). Mendoza et al. (2011) found a $30 \mathrm{~km}$ wide deformation belt situated on the main trace of the fault system which moves horizontally with a relative average velocity of $4.4 \pm 0.6$ (east) and $-0.3 \pm 0.4$ (north) $\mathrm{mm}$ /year. Recent studies indicate that the movement across the MFFS is $5.9 \pm 0.2 \mathrm{~mm} /$ year (Mendoza et al., 2015).

Seismicity studies have been carried out in this area since the $90 \mathrm{~s}$ when the installation of seismic instrumentation started. At present lit-

* Corresponding author.

Email address: cbuffoni@fcaglp.unlp.edu.ar (C. Buffoni) 


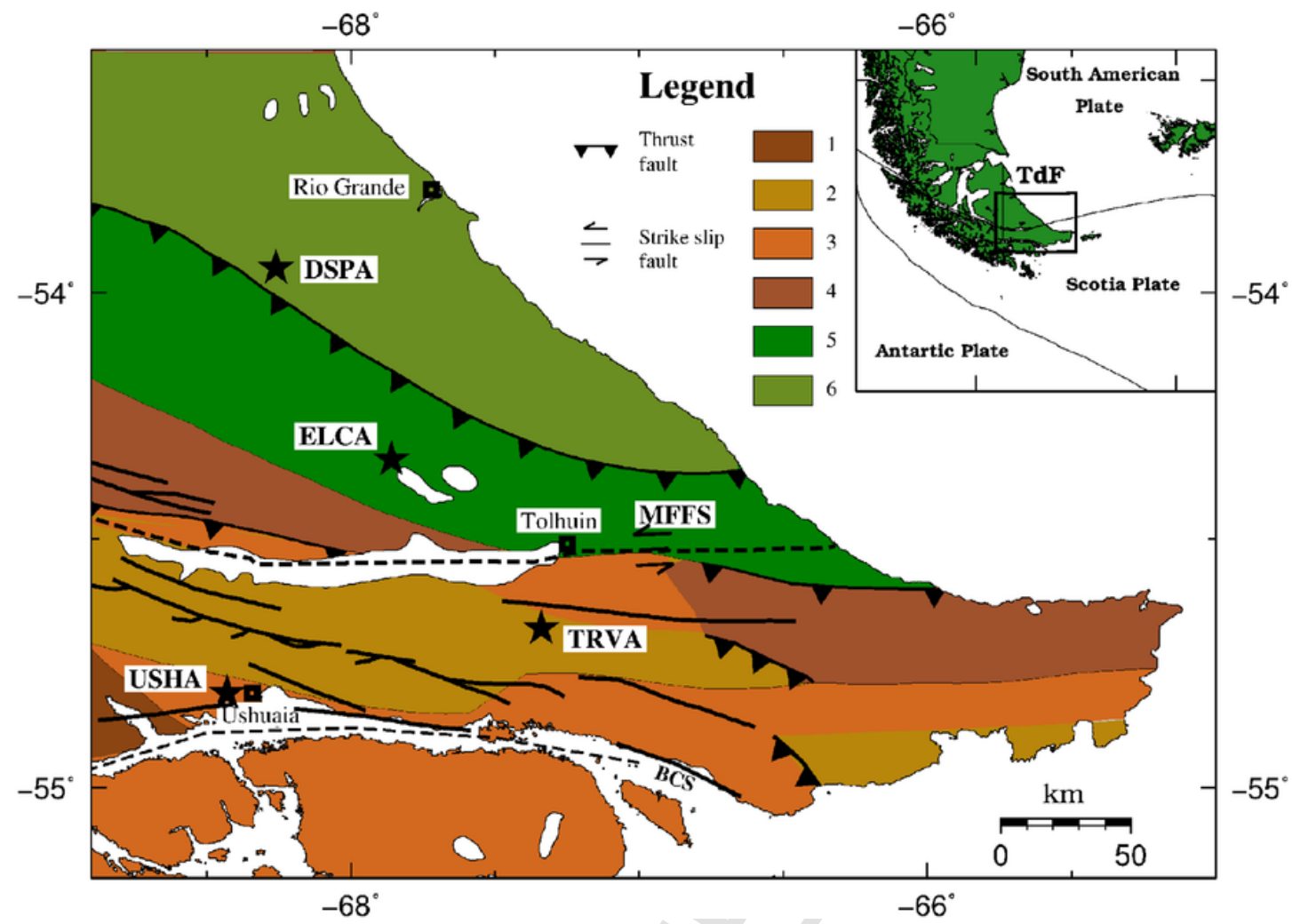

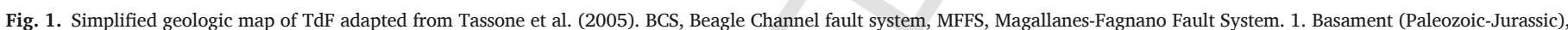

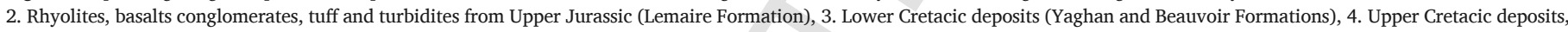

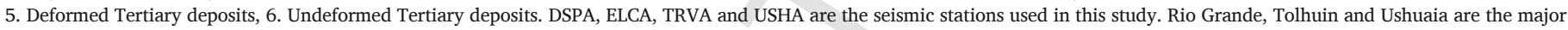
cities. The different geologic units were determined by several authors (Caminos and Nullo, 1979; Caminos et al., 1981; Olivero and Martinioni, 2001; Ghiglione, 2003).

tle data is available for TdF. The station deployment and maintenance are expensive since $\mathrm{TdF}$ is a remote area with rough climate. In this study we used data recorded at four broadband seismic stations: DSPA, ELCA and TRVA belong to the Faculty of Astronomical and Geophysical Sciences, National University of La Plata (FCAG-UNLP) and to the National Institute of Oceanography and Experimental Geophysics (OGS) and are locally operated by the Astronomical Station of Rio Grande (EARG); USHA belongs to the Comprehensive Nuclear-test-ban Treaty Organization (CTBTO) and its local responsible is the National Institute of Seismic Prevention (INPRES). In general the seismicity in TdF suggests a rather continuous release of energy in low magnitude events (Febrer et al., 2000; Lodolo et al., 2003; Sabbione et al., 2007; Buffoni, 2008; Buffoni et al., 2009). Nevertheless, from existing tectonic descriptions and big historical earthquakes located in the region (Lomnitz, 1970; Jaschek et al., 1982), this area is considered as a very seismically active one. The historical earthquake records include a magnitude 7.0 event in 1879 (Lomnitz, 1970), several earthquakes of magnitude $>6$ during 1930 and 1944 and two important events in 1949 December 17 of magnitude 7.5 and 7.8 (Jaschek et al., 1982).

Determination of crustal structure is essential for any seismic interpretation since it permits more accurate earthquake locations for a better mapping of fault systems and stress fields. The motivation of the present study is to investigate the structure of the crust beneath TdF. Only a few studies have been carried out to constrain the crustal structure and Moho depth near this area. Ludwig et al. (1965) presented the results of 22 seismic refraction on-shore and off-shore profiles, in the Magallanes Strait, situated in the Chilean western part of $\mathrm{TdF}$, obtaining a crustal thickness of $29.6-34.8 \mathrm{~km}$. Robertson Maurice et al. (2003) obtained a crustal thickness between 26 and $36 \mathrm{~km}$ inferred from regional seismograms inversion. Lawrence and Wiens (2004) per- formed receiver functions (RFs) and surface wave analyses to constrain the crustal and upper mantle structure of Chilean Patagonia, suggesting a Moho ranging from 28 to $34 \mathrm{~km}$ depth. We present here the first teleseismic RF and ambient seismic noise autocorrelation analysis for the Argentinian part of TdF. Both methods are independent and their consistent results can provide confidence into the obtained models.

\section{Geological and tectonic background}

The present geological and tectonic setting of TdF is the result of the complex evolution of southernmost South America associated with the Mesozoic-Cenozoic Andean orogenic cycle, involving the interaction between the South American, Scotia and Antartic plates (Fig. 1). This region has been affected by at least three complex tectonic regimes: extensional in the late Jurassic-early Cretaceous, contractional from the Cretaceous-Paleocene and strike-slip from the Oligocene onwards (Menichetti et al., 2008).

The southern part of TdF presents strong morphological evidence of Quaternary activity related to the E-W sinistral strike-slip regime while the northern area is affected by extensional tectonics associated to normal fault systems of the eastern arms of Magallan Strait (Menichetti et al., 2008). The more recent tectonic evolution of South America is related to the Scotia plate motions which relocated continental fragments over $1.000 \mathrm{~km}$ from TdF (Dalziel et al., 1975).

The western trace of the main left-lateral transcurrent deformation between the South American and Scotia plates, consists of a strike-slip lineament trending E-W across the Island and forming the MFFS. This fault system has been considered as the expression of the suture between the South American and Scotia plates like a continental transform fault (Olivero and Martinioni, 2001). The principal trace of the 
MFFS is, in fact, a series of vertical fault segments arranged with en echelon geometry (Smalley et al., 2003; Lodolo et al., 2003). In the region of the Fuegian Andes, to the SW of our study area, evidence of fault-slip data showed that the strike-slip regime along the MFFS has been active since at least the latest Eocene (Olivero and Martinioni, 2001), indicating the relative importance of strike-slip and dip-slip faulting in the area. The main trace of the MFFS, named the Magallanes-Fagnano Fault (MFF), is one of the set of subparallel strike-slip lineaments: the Beagle Channel, Lasifashaj, Deseado, Carbajal Valley and Rio Turbio are some of other faults (Klepeis, 1994; Menichetti et al., 2008). The MFF and these secondary fractures overprint the fold-and-thrust belt and are the responsible for the present complex tectonic setting of the area.

\section{Receiver functions}

The RFs technique has been widely used to image the crustal structure beneath individual seismic stations (Phinney, 1964; Ammon, 1991; Ammon and Zandt, 1993; Mangino et al., 1993; Zhu and Kanamori, 2000; Gilbert et al., 2006; Perarnau et al., 2010; Gans et al., 2011; Ammirati et al., 2013; Ryan et al., 2016). In the present study we employed the P-wave radial RFs technique and applied the iterative time domain deconvolution technique developed by Ligorría and Ammon (1999) to isolate the P-to-S (Ps) converted phases and other reverberations. This method is based on the Kikuchi and Kanamori (1982) iterative deconvolution algorithm that applies a low-pass Gaussian filter to the data before the deconvolution is performed and calculates the RFs by minimizing the difference between the observed radial seismogram and the convolution of the iteratively updated RFs with the observed vertical seismogram.

We employed additionally the H-k stacking method developed by Zhu and Kanamori (2000) for the simultaneous estimation of crustal thickness $(\mathrm{H})$ and $\mathrm{Vp} / \mathrm{Vs}$ ratio $(\mathrm{k})$. In applying this technique it is necessary to select weighting factors for the Ps conversion and its multiples. We use different weights to avoid a possible bias and to see how sensitive our results are due to the chosen weighting values. For this end, we adopted the following criteria: a) $\mathrm{w}_{1}>\mathrm{w}_{2}>\mathrm{w}_{3}$, b) $\mathrm{w}_{1}+\mathrm{w}_{2}+\mathrm{w}_{3}=1$ and c) $\mathrm{w}_{1} \geq 0.5$, where $\mathrm{w}_{1}, \mathrm{w}_{2}$ and $\mathrm{w}_{3}$ are the weighting factors of the Ps, $\mathrm{PpPs}$ and PpSs + PsPs conversions, respectively. Here we will compare the stacking results for the different combination of weights to show that our results do not depend on a single set of empirically chosen values. Further, we assume a constant average crustal velocity of $6.1 \mathrm{~km} / \mathrm{s}$ based on.

the model obtained by Lawrence and Wiens (2004) at the seismic station VTDF located in Estancia Vicuna, Tierra del Fuego $\left(-54.14^{\circ}\right.$, $\left.-68.71^{\circ}\right)$ and applied the H-k stacking method together with a bootstrap algorithm ( $N=200$ repetitions) to assess the robustness of the final results.

\subsection{Data}

The data used in this study have been recorded at four seismic stations installed in the Argentinian part of TdF: DSPA, ELCA, TRVA and USHA. The station positions are marked by a star in the map of Fig. 1 . All stations are broadband (Güralp CMG-3T, CMG-3TD, CMG 40T and Streckeisen seismometers), located at remote sites and are solar powered.

Teleseismic data recorded by the four stations were analyzed in order to calculate the radial P-wave RFs. We considered events with magnitudes $\mathrm{mb}>5.5$ and epicentral distances between $30^{\circ}$ and $90^{\circ}$. The distance range has been chosen to avoid triplicated phases from the upper and lower mantle transition zones. We visually selected between 40 and 116 teleseismic events conforming data availability and quality at each station (Fig. 2 and Table 1).

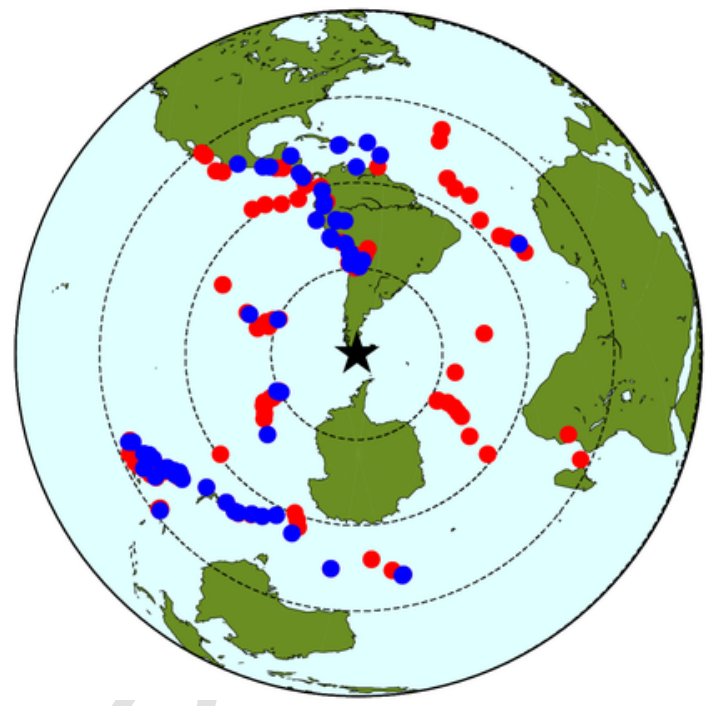

Fig. 2. Epicentral location of all analyzed events (red and blue dots) and selected events with good quality RFs (blue dots). TdF (star) is at the center of the map. The three concentric circles mark epicentral distances of $30^{\circ}, 60^{\circ}$ and $90^{\circ}$. (For interpretation of the references to color in this figure legend, the reader is referred to the web version of this article.)

Table 1

Teleseismic events considered at each seismic station used to calculate the RFs (marked as red dots in Fig. 2), and the selected RFs with good quality (the corresponding events have been marked as blue dots in Fig. 2).

\begin{tabular}{lllll}
\hline Station code & $\begin{array}{l}\text { Lat } \\
(\mathrm{deg})\end{array}$ & $\begin{array}{l}\text { Lon } \\
(\mathrm{deg})\end{array}$ & Events used & RFs selected \\
\hline TRVA & -54.68 & -67.34 & 116 & 42 \\
USHA & -54.81 & -68.43 & 52 & 27 \\
DSPA & -53.95 & -68.26 & 101 & 25 \\
ELCA & -54.34 & -67.85 & 40 & 12 \\
\hline
\end{tabular}

Noisy data or data without clear P onsets have been removed from our analysis. We used the Seismic Analysis Code (Goldstein and Snoke, 2005) software to pre-process the seismograms. The data have been cut using $85 \mathrm{~s}$ windows which started $5 \mathrm{~s}$ before the P-wave arrival. The data were band-pass filtered in the frequency range of $0.02-1 \mathrm{~Hz}$. Using low frequency RFs may reduce the potential for biased results caused by scattered energy (Mangino et al., 1993). However, the selection of a low frequency range may complicate the identification of shallow discontinuities. Therefore we have tested different frequency bands and selected the one which provided the better waveforms. A low-pass Gaussian filter with a width factor $\mathrm{a}=2.5(\sim 1 \mathrm{~Hz})$ was applied before deconvolution.

\subsection{Analysis and results}

RFs without a clear Ps conversion from the Moho and without a first positive pulse at $0 \mathrm{~s}$ (direct P-wave arrival) were removed from the following analysis. After data processing and RF selection (see previous section) we retain a total of 106 RFs (Table 1). The recovery percentage of the radial waveform was evaluated by the RMS (Root Mean Square) between the original radial waveform and the convolution between the radial RF with the original vertical component. All the selected RF were visually inspected controlling the coherence of the waveform and the stability. Approximately, the $86 \%$ of the selected RFs have a correlation or misfit value $>70 \%$ (Fig. S1 in the Supplementary material section). RFs with a misfit $>60 \%$ still contributed 
positively to one or the other reverberation and were therefore not retained from the analysis.

RFs for all the broadband stations are shown as a function of back azimuth in Fig. 3. It can be seen from Fig. 3 (and Fig. 2) that the selected events are basically located in the SW and $\mathrm{N}$ of TdF. I.e., the events used for this analysis group into two back azimuth corridors: group SW (events to the SW of TdF) and group $\mathrm{N}$ (events to the $\mathrm{N}$ of TdF). This means that the corresponding piercing points of the Moho conversions and reverberations are also clustered into two groups for each station (see red crosses in Fig. 8 in Section 5). We therefore divide the data into two groups according to the piercing point distribution of the selected RFs for the subsequent study.

A visual inspection of the RFs from Fig. 3 shows a certain degree of waveform complexity. Simple waveforms cannot be expected due to the complex geological settings. The map in Fig. 1 shows that the sta- tions are all located close to fault systems at the margins of different tectonic units. Nevertheless, the RFs obtained show that the energy is mostly concentrated in their radial components (Fig. S2 in the Supplementary material section) and not in the transverse ones which gives us the confidence that the lateral homogeneous model assumption is still a valid approximation for our data. In all RF sections we can identify the Ps conversion from the Moho between 3 and $4.5 \mathrm{~s}$. The PpPs and PpSs + PsPs reverberations are difficult to identify in some groups due to the waveform complexity of our RF data.

The PpPs and PpSs + PsPs reverberations were not observed for the groups. In the case of TRVA, it seems that these multiples are observed at only some RFs (see the black dotted rectangles in Fig. 3a). RFs from stations DSPA and ELCA show similar to more waveform complexity. The Ps conversion from the Moho is observed between 3 and $3.5 \mathrm{~s}$ at DSPA and a little later at ELCA. In the case of DSPA, a large positive a)

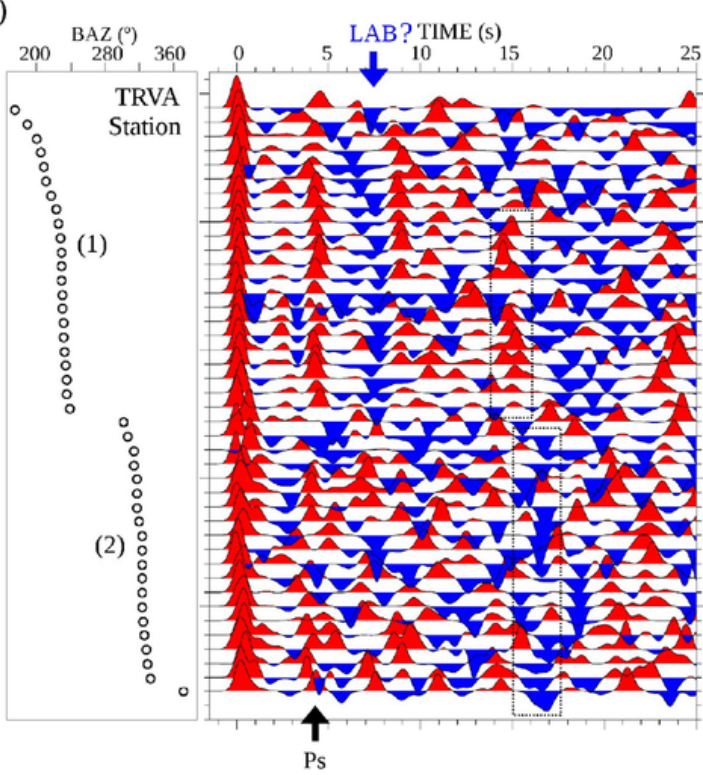

c)

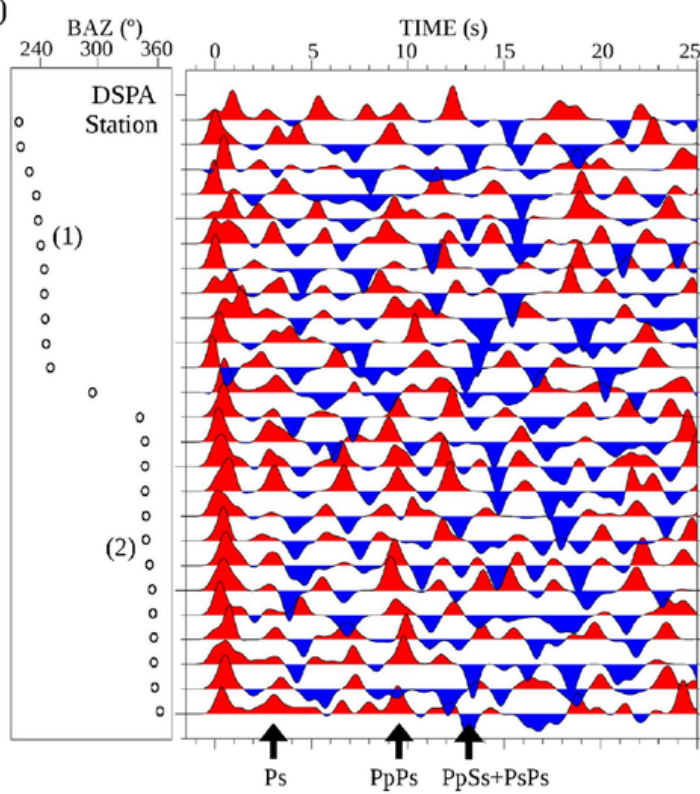

b)

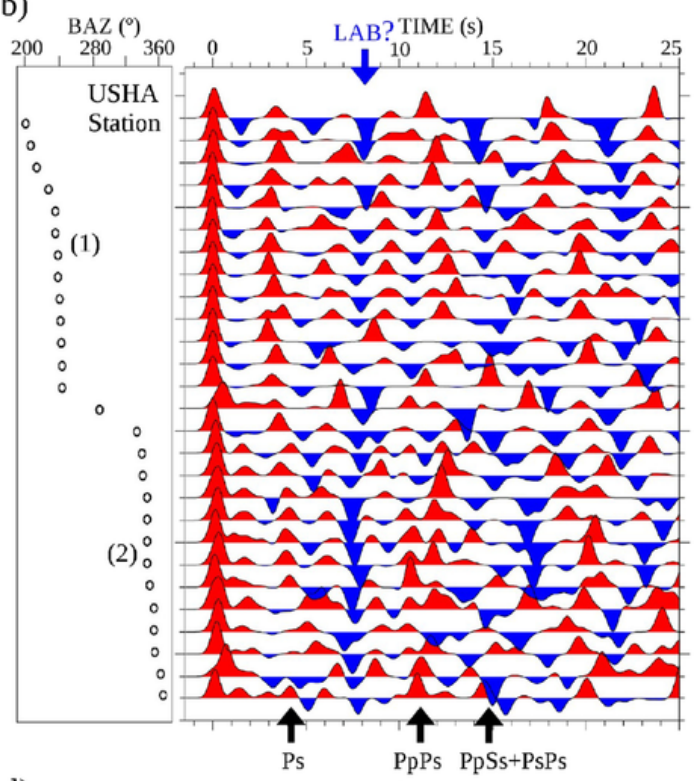

d)

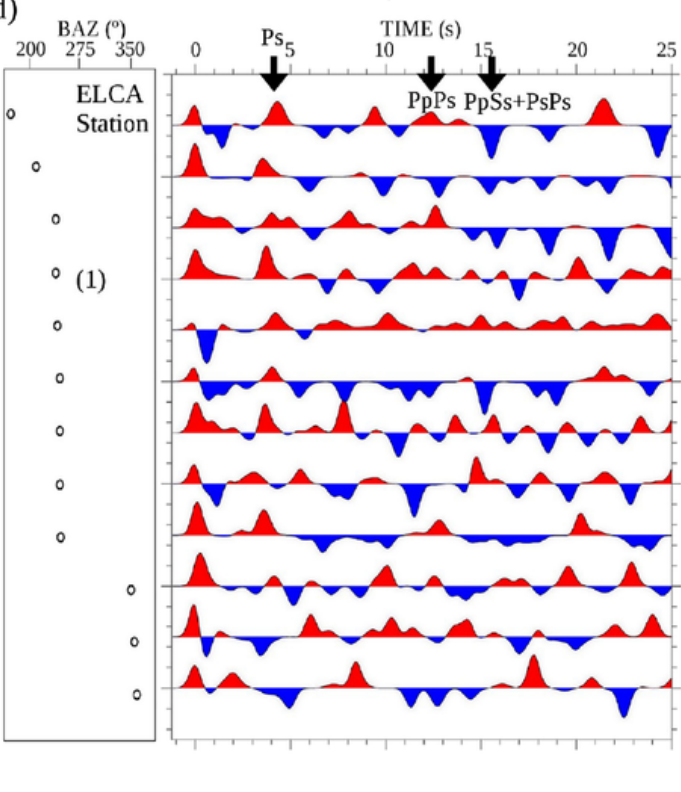

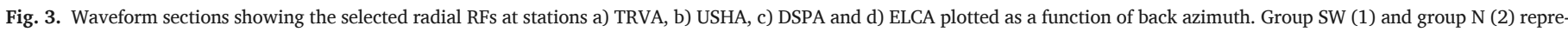

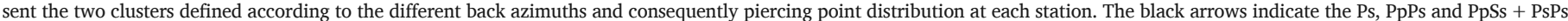
conversions. The black dotted rectangles in panel a mark the PpPs (with positive polarity) and the PpSs + PsPs conversions (with negative polarity) observed at TRVA. 
phase between 9 and $9.5 \mathrm{~s}$ is observed for events to the $\mathrm{N}$ and is related to the PpPs reverberation that is observed a little later for group SW but not for all RFs. Taking into account the division in two groups, the Ps phase was generally better identified with more energy for group SW at stations TRVA and USHA. Regarding DSPA, the Ps was better observed at group $\mathrm{N}$ and the waveforms at group SW show more complexity. Unfortunately, for station ELCA we obtained only few good quality RFs which all are for events to the SW of TdF and therefore the analysis was only performed for this group.

Besides the Moho reflections, the RFs contain also signals from other discontinuities. Most striking is the observation of a likely negative reverberation which can be seen at about $6.5-8 \mathrm{~s}$ at TRVA (Fig. 3a) for events to the SW and at USHA (Fig. 3b) for almost all events. This phase could be a P-to-s wave conversion from the seismic lithosphere-asthenosphere boundary (LAB) at about $80 \mathrm{~km}$ depth or a
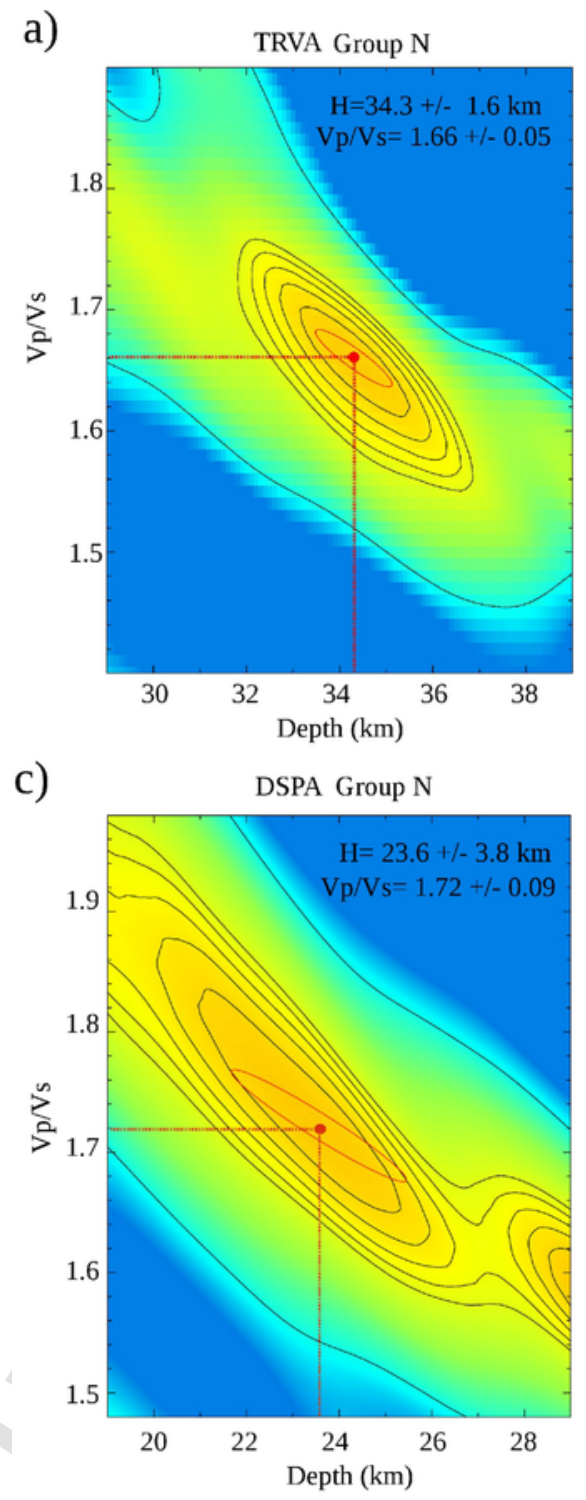

PpSs + PsPs reverberation from an interface at about 6-7 km depths in the southern part of the island. We did not further investigate this signal, but we favour the LAB interpretation since this signal is quite clear and strong for a shallow structure PpSs + PsPs reverberation.

\subsubsection{H-k stacking method}

We applied the H-k stacking technique (Zhu and Kanamori, 2000) to the different groups of selected RFs at each seismic station. According to the criteria adopted in this study (see Section 3 for details), eight solutions of Moho depth and $\mathrm{Vp} / \mathrm{Vs}$ ratio were obtained for each group at each seismic station taking into account the different possible combinations of weighting factors for the Ps conversion and its multiples. An example of one solution at one group for all stations is shown in Fig. 4. The selected weighting factors in this example are $\mathrm{w}_{1}=0.7$ (Ps), $\mathrm{w}_{2}=0.2$ (PpPs) and $\mathrm{w}_{3}=0.1$ (PpSs + PsPs). Despite of the

b)

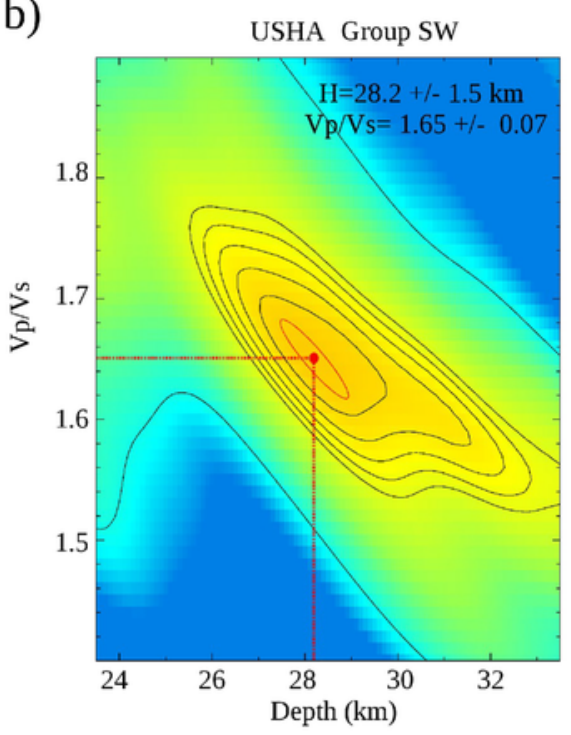

d)

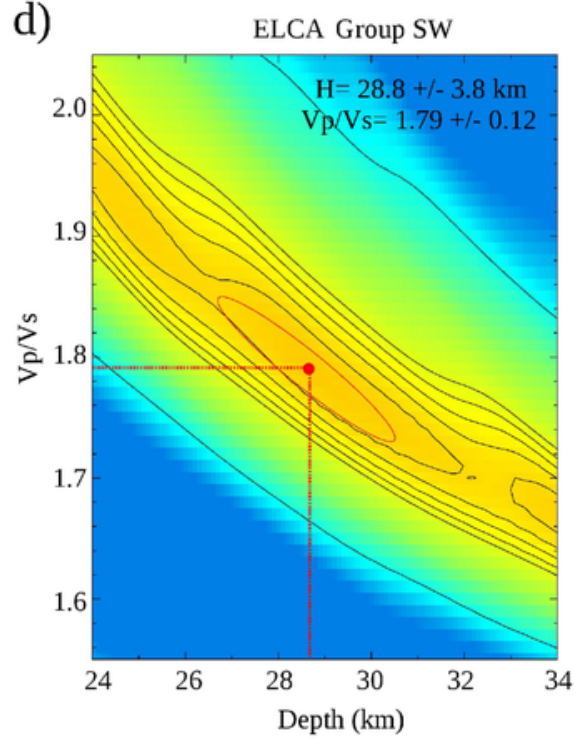

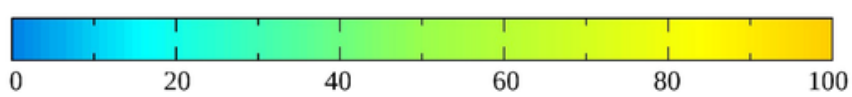

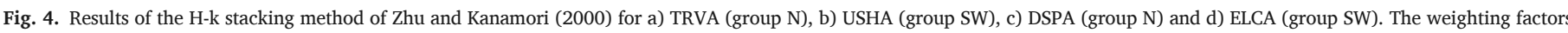

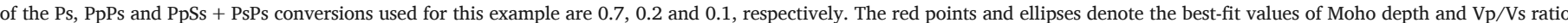

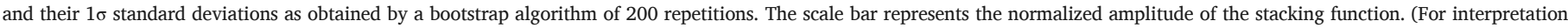
of the references to color in this figure legend, the reader is referred to the web version of this article.) 
waveforms complexity of some RFs (Fig. 3) there exist only one maximum which is reasonably well defined.

The solutions obtained when applying different weights at each group for all the stations are shown in Fig. 5. The crustal thickness and $\mathrm{Vp} / \mathrm{Vs}$ values range between $23.3-34.8 \mathrm{~km}$ and $1.63-1.80$ depending on the seismic station, the piercing point group and the combinations of weighting factors used. The solutions for the different combinations of the H-k weighting factors cluster closely around their mean. The lowest and the highest value of crustal thickness obtained with this technique were found at stations DSPA and TRVA suggesting an increase of crustal thickness from north to south in the study area. The average values of the standard deviation for these results (each group is considered individually) are $0.3 \mathrm{~km}$ and 0.02 for $\mathrm{H}$ and $\mathrm{Vp} / \mathrm{Vs}$, respectively. The minimum and maximum values of standard deviation on Moho depth are $1.5 \mathrm{~km}$ (USHA, group SW) and $3.8 \mathrm{~km}$ (ELCA, group SW), respectively. Regarding to the standard deviation on $\mathrm{Vp} / \mathrm{Vs}$, the minimum value was found for group 1 of TRVA (0.05) and the maximum value was found for group SW of USHA (0.2). At all stations the obtained solutions group closely around the mean which shows that the measurements are robust with respect to changes of the weighting factors to provide confidence into the results.

\subsubsection{RF inversion with the neighbourhood algorithm}

In order to provide velocity-depth profiles for the crustal structure beneath each station, the radial RFs have been inverted using the non-linear Neighbourhood Algorithm (NA) developed by Sambridge (1999). This method requires a starting model and randomly investigates the multidimensional parameter space to find a set of models that produces a synthetic RF most closely fitting the observed waveform. The NA strategy (Sambridge, 1999) makes use of Voronoi cells to sample the model space in an efficient way to find its good data-fitting regions. In our analysis the parametrized starting model contains six layers with 24 parameters, the S-wave velocity at the top and the bottom of each layer, the thickness and the $\mathrm{Vp} / \mathrm{Vs}$ ratio for the layer (Table 2). We used RFs calculated from $5 \mathrm{~s}$ prior the direct P-wave arrival to $30 \mathrm{~s}$ after the P-wave arrival and stacked the selected RFs for the different data groups at each station. The inversions were based on 200 iterations with different numbers of generated models and Voronoi cells in each iteration. The final inversion results converged to a preferred model class which did not vary significantly for the different starting models and inversion parameters.

Fig. 6 shows the final results obtained for all the stations. The parameter space is indicated by the black lines in Fig. 6a, b, e, f, i, j and $\mathrm{m}$. The grey lines mark the sampled models and the green area indicates the density of the 1000 best models, the color being logarithmically proportional to the number of models, as shown by the scale bar. The

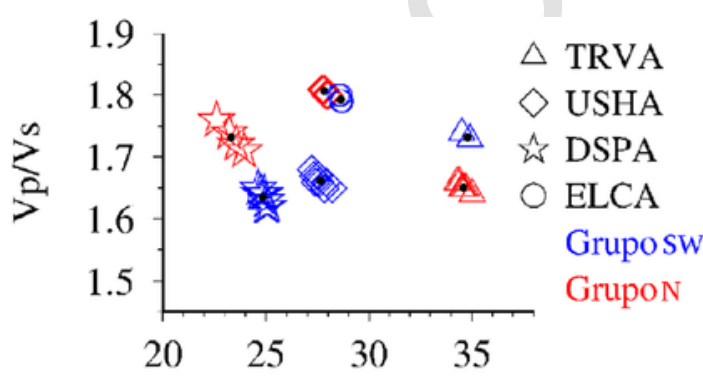

$\mathrm{H}(\mathrm{km})$

Fig. 5. H-k stacking results for different weights at each group and all stations used in this study. Different symbols and colors have been used to mark the different stations and event groups, respectively. The black points mark the mean values of Moho depths (H) and $\mathrm{Vp} /$ Vs ratios (group SW in blue and group $\mathrm{N}$ in red). (For interpretation of the references to color in this figure legend, the reader is referred to the web version of this article.)
Table 2

Parametrization of the starting model used in the NA inversion. The table shows minimum and maximum values of thickness, S-wave velocity at the top and the bottom of each layer and the $\mathrm{Vp} / \mathrm{Vs}$ ratio each the layer.

\begin{tabular}{llllllllll}
\hline Layer & $\mathrm{H}$ & & $\mathrm{V}_{\mathrm{S} 1}$ & & $\mathrm{~V}_{\mathrm{S} 2}$ & \multicolumn{3}{c}{$\mathrm{V}_{\mathrm{P}} / \mathrm{V}_{\mathrm{S}}$} \\
\hline & Min & Max & Min & Max & Min & Max & Min & Max \\
\hline 1 & 0 & 5 & 1.75 & 3.20 & 1.75 & 3.20 & 1.65 & 2.20 \\
2 & 5 & 15 & 3.20 & 4.00 & 3.20 & 4.00 & 1.65 & 1.85 \\
3 & 5 & 20 & 3.20 & 4.00 & 3.20 & 4.00 & 1.65 & 1.85 \\
4 & 10 & 20 & 3.60 & 4.50 & 3.60 & 4.50 & 1.65 & 1.85 \\
5 & 10 & 30 & 4.00 & 5.00 & 4.00 & 5.00 & 1.65 & 1.85 \\
\hline
\end{tabular}

best data-fitting Vs and Vp/Vs ratio are shown in red. The stacked RF data and corresponding best fitting synthetic RFs are shown as black and red lines in Fig. 6c, d, g, h, k, j and n.

At stations TRVA and USHA the minimum misfit velocity model shows a crustal thickness larger than $30 \mathrm{~km}$ in the southern part of our study area. Here, crustal thickness is defined by an S-velocity increase to values larger than $4.2-4.6 \mathrm{~km} / \mathrm{s}$. The best models for the $S W$-group of USHA show velocities which are too high for the upper-most crust and which could be caused by the presence of shallow dipping interfaces which are not modeled by our inversion approach. For stations DSPA and ELCA the Moho depth obtained in the inversion ranges between 24.5 and $27.7 \mathrm{~km}$, suggesting that the crust is thicker in the southern part of TdF than in the north, which is in concordance with the results for the H-k stacking. We analyzed the uncertainty of our results considering the Moho depth variation for all models that have a misfit value less than the minimum plus an empirical value of $10 \%$. As uncertainty we used two standard deviations as this value represents the $95.44 \%$ of all models considering a Gaussian distribution. The uncertainty value found for the Moho depth ranges between $0.7 \mathrm{~km}$ and $2 \mathrm{~km}$, while considering the $\mathrm{V}_{\mathrm{P}} / \mathrm{V}_{\mathrm{S}}$ ratio the uncertainty ranges from 0.01 to 0.029 . The highest and lowest values were observed for group SW at stations ELCA and TRVA, respectively.

The individual RFs have also been inverted in a similar way to the stacked RFs. The inversion of individual RFs has the advantage that no move-out corrections are applied. Move-out corrections for the Ps phase over large epicentral distance ranges may lead to misalignment and amplitude underestimation of the multiply reflected conversions. This may bias the inversion results. Stacking the RFs, however, simplifies the waveforms through enhancing the signals caused by the average structure. The final models of the individual RF inversions converged to models which are comparable to the models of the stacked RFs (see Appendix A), also for the N-groups where the distance range is largest.

\section{Ambient seismic noise autocorrelation}

Ambient noise autocorrelations are becoming a popular single-station approach to extract zero-offset Green's functions in full analogy to ambient noise cross-correlations. The zero-offset Green's function for a one-dimensional (1-D) medium is the reflection response of the local structure beneath the station. Claerbout (1968) already showed that in this case the reflection response can be obtained from the autocorrelation of the plane wave transmission response. Later, Wapenaar et al. (2004) among others extended this idea to two-dimensional (2-D) and three-dimensional (3-D) acoustic and elastic media. Recently, this concept is being used to retrieve Moho reflected waves through the cross-correlation (e.g., Zhan et al., 2010; Ruigrok et al., 2011) and the autocorrelation technique (Tibuleac and von Seggern, 2012; Gorbatov et al., 2013, Kennett et al., 2015; Taylor et al., 2016; Oren and Nowack, 2017; among others), and to map the basement of geological basins (Romero and Schimmel, 2018). The Green's function extraction re- 
a)

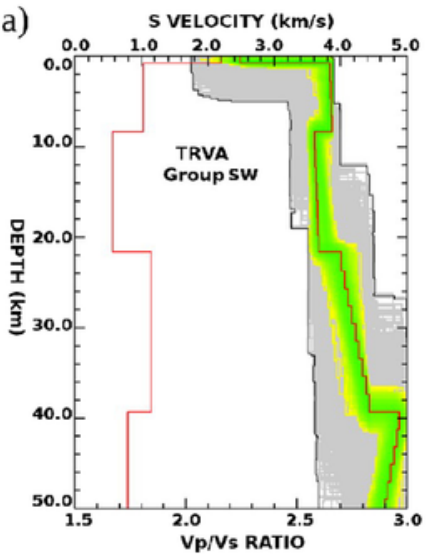

e)

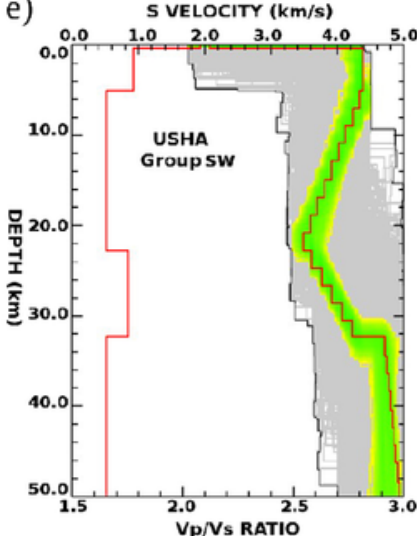

i)

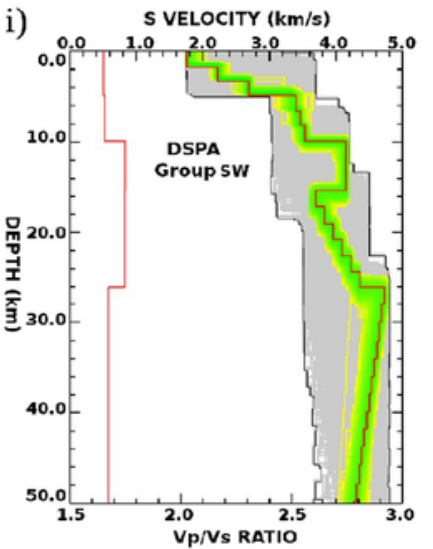

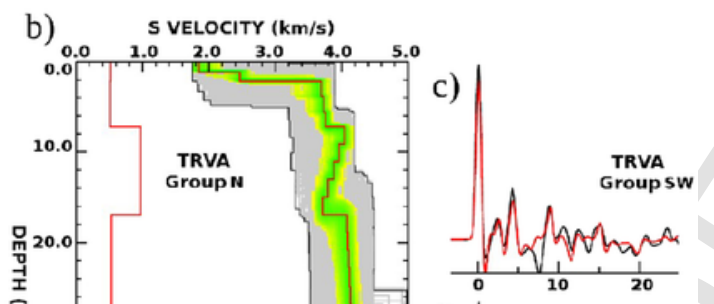

d)
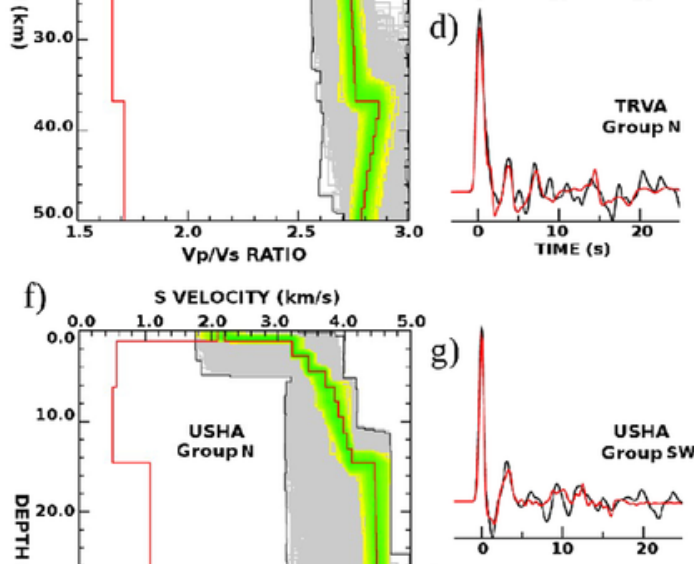

h)
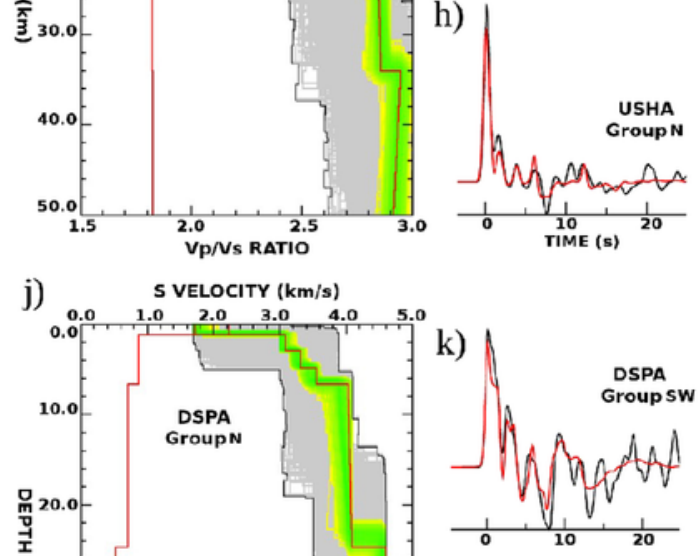

l)

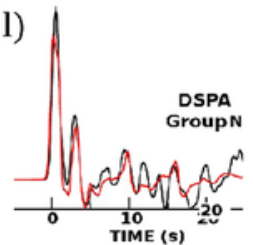

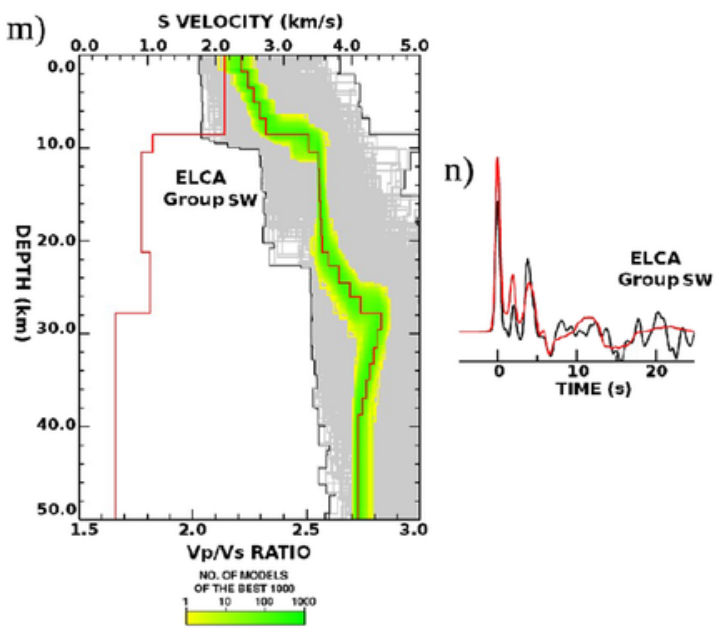




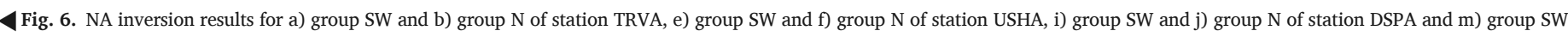

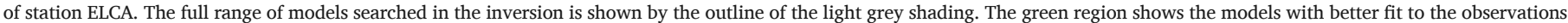

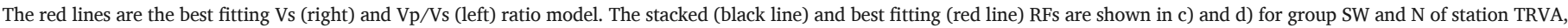

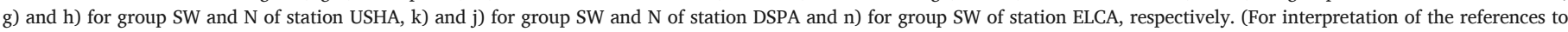
color in this figure legend, the reader is referred to the web version of this article.)

quires diffuse wave fields which in practice is usually not the case. Consequently, Green's functions are likely not fully reconstructed and we therefore refer to the empirical Green's Function (EGF). Ambient seismic noise is continuously registered at all stations in TdF and we used these records to obtain the Moho depth beneath each station by applying the autocorrelation approach.

\subsection{Method and results}

For retrieval of the reflection response from the recorded ambient seismic noise at the four broadband stations in TdF, we applied the phase cross-correlation (PCC) developed by Schimmel (1999). The PCC is amplitude-unbiased since it employs only the instantaneous phases of analytic signals which therefore permits a robust signal detection and fast convergence to an empirical Green's function (e.g., Schimmel et al., 2018). The noise autocorrelations were calculated using the vertical component of 1 year of continuous records (2008). Seismic traces containing spikes or gaps were removed from further processing in order to ensure data quality. The vertical records were split into 24 hours-long segments, followed by the subtraction of the mean and trend, decimation, removal of the instrument response and band-pass filtering between 0.7 and $2 \mathrm{~Hz}$.

In order to improve the signal emergence through their coherent appearance, Schimmel and Gallart (2007) developed the time-frequency domain phase-weighted stack (tf-PWS). This technique is an extension of the time-domain phase-weighted stack (PWS) presented by Schimmel and Paulssen (1997) which is a non-linear stack where each sample of a linear stack is weighted by an amplitude-unbiased coherence measure. The tf-PWS is based on the time-frequency decomposition of each trace using the S-transform (Stockwell et al., 1996).

After the autocorrelation, we stacked the traces every 4 days by applying the tf-PWS technique. Fig. 7 shows the results of the stacked auto-correlograms obtained at each seismic station. The measured two-way traveltime of the Moho reflections have been converted to depth using an average velocity $6.1 \mathrm{~km} / \mathrm{s}$ and the average velocity computed from the final NA inversion results. Depending on the seismic station, the first arrival observed at time lags between $9 \mathrm{~s}$ and $11 \mathrm{~s}$ is interpreted as the two-way traveltime of a PmP Moho reflection (see green arrows in Fig. 7). This reflection is better observed at stations DSPA and USHA. A change in the PmP reflection pattern is observed at TRVA and is likely related to the presence of sediments in that area. Regarding to ELCA, several multiple reflections are observed and likely related with reverberations in sedimentary layers.

The autocorrelation results are compared with the expected PmP and SmS Moho reflections based on our H-k stacking and NA inversion models (red and blue dotted lines in Fig. 7, respectively). With the autocorrelation approach we cannot distinguish different reflection point areas and we therefore just averaged the H-k and NA models per station to obtain a rough travel time prediction. In most cases, the autocorrelations contain consistent signals that appear close to the expected reflections. The misfit is likely related to heterogeneities and Moho topography. In fact, the zero-offset stationary-phase reflection point differs from the conversion points and is shifted by the existing Moho topography. A $1 \mathrm{~s}$ two-way-travel time difference translates into a $3 \mathrm{~km}$ depth variation which is in the order of the observed Moho depth variations per piercing point group. We did not further analyze the observed discrepancies between the different methods.
The SmS and PmS reflections are shown for completeness. They were also observed by Tibuleac and von Seggern (2012) and Oren and Nowack (2017). Their observation reduces possible ambiguities in the PmP identification and is likely due to energy which does not arrive from directly below the station. At least at station DSPA, we observe an SmS arrival while the SmS and SmP identification is more ambiguous for the other stations.

\section{Discussion and conclusions}

At all the stations the RFs and corresponding models are complex, indicating that the crust beneath this region is not simple. Despite this, it was possible to estimate values of crustal thickness using two seismic sources: teleseismic events and ambient seismic noise. A compilation of Moho depth and Vp/Vs ratio values obtained with all the methods applied is shown in Fig. 8 and in Table 3.

Values of crustal thickness in the Argentinian part of TdF vary within about the same range when applying the H-k stacking $(23.3-34.8 \mathrm{~km})$, the NA method (24.5-39.2 km) and the autocorrelation of ambient seismic noise (27-34.1 km). These results compare well with previous studies for neighboring regions, e.g., with seismic refraction in the Magallanes Strait (located at the west of the study area) developed by Ludwig et al. (1965), obtaining values ranging from 29.6 to $34.8 \mathrm{~km}$; with the results of regional waveform inversion in Patagonia area $(26-36 \mathrm{~km})$ presented by Robertson Maurice et al. (2003) and with the crustal thickness inferred from RF and surface wave inversion estimated by Lawrence and Wiens (2004) obtaining a Moho depth of $28-34 \mathrm{~km}$ in the Patagonia area. In general the Moho observed in our data is shallow in the northern and central part of TdF and becomes deeper in the southern part of the Island when considering the results obtained with the NA and the autocorrelation methods. Moho depths have also been controlled by the H-k stacking method. The increase in crustal thickness from north to south is also observed at almost all stations when applying the method developed by Zhu and Kanamori (2000). This crustal thickening along the folded and tectonically active region seems likely to be associated with the contractional eposide during the Cretaceous-Paleocene (Menichetti et al., 2008). Several strike-slip faults associated with normal faults dipping northward are present in the southern part of TdF (Menichetti et al., 2008). Reverberations associated with dipping discontinuities can be difficult to identify due their variations in arrival time and amplitude as a function of back azimuth and epicentral distance (Cassidy, 1992). In the case of USHA, a big difference is observed in the crustal thickness values obtained with the H-k stacking method and the NA inversion. The presence of dipping faults is likely interfering with the identification of the multiple phases at this station. Regardless of that, the solutions obtained for all groups and stations are robust when applying the H-k stacking technique with different weighting factors.

The crustal thickness estimated with the ambient seismic noise autocorrelation is sound with those values obtained using the RF method. The major difference is observed at station ELCA. This station is located at the central part of the study area where the biggest Cenozoic sedimentary thickness is present (Olivero and Martinioni, 2001; Tassone et al., 2005; Menichetti et al., 2008). Several reflections can be observed from Fig. 7b (Section 4.1) that may hide the real PmP Moho reflection at station ELCA. In this case, we interpreted that the first strong reflection (at $\sim 10.7 \mathrm{~s}$ ) observed in almost all autocorrelations is the PmP Moho reflection, but the results obtained with the RFs 


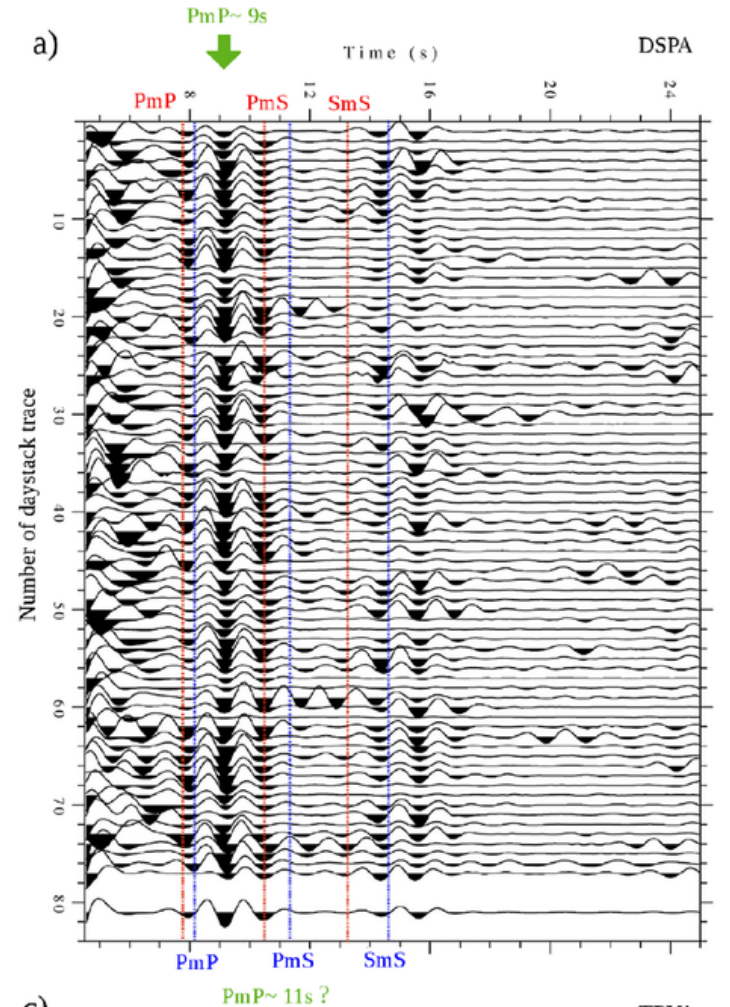

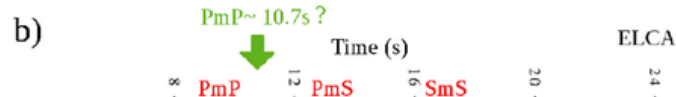
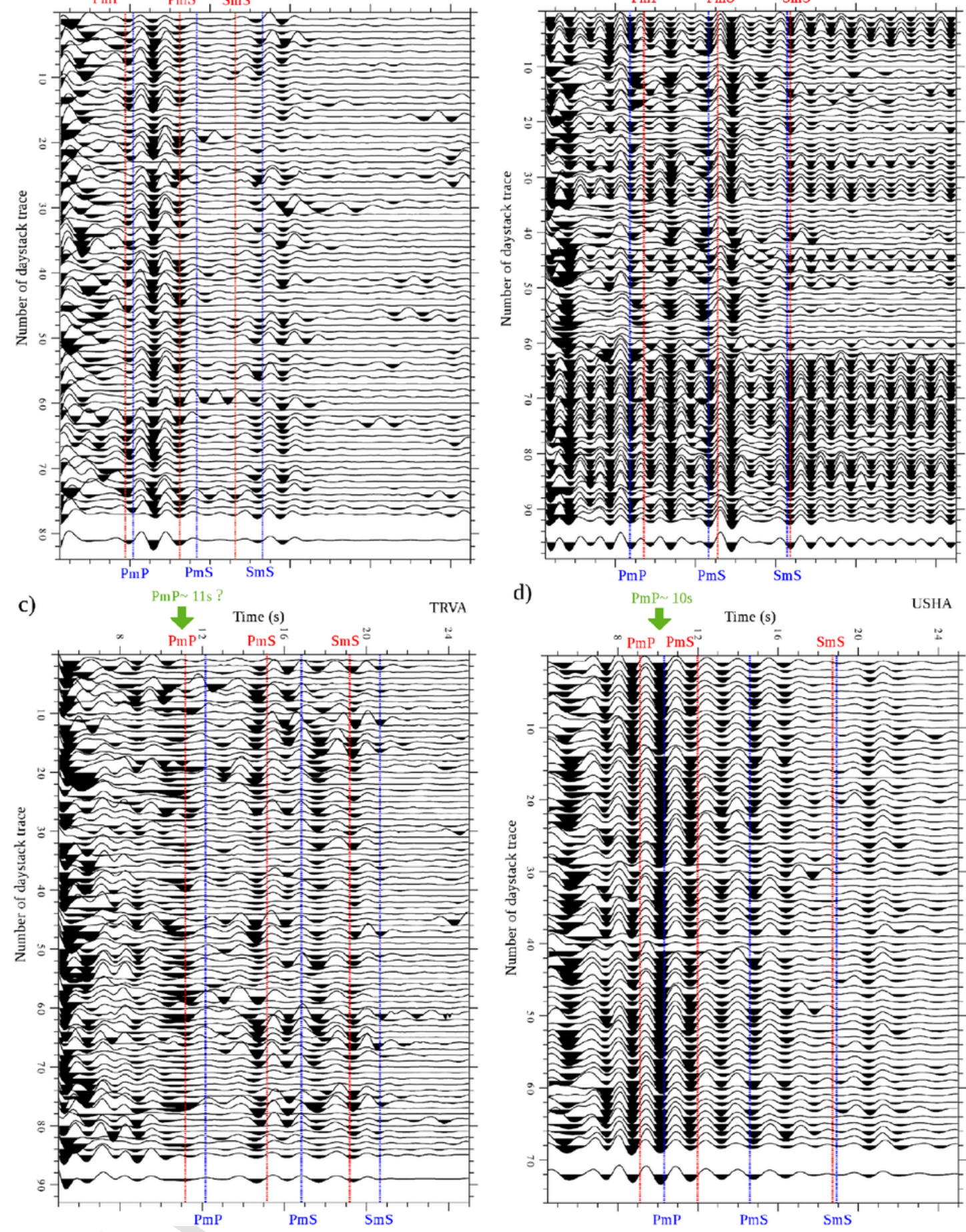

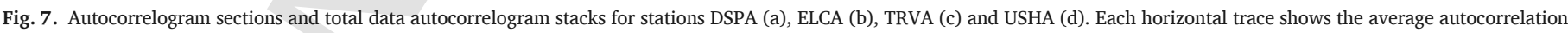

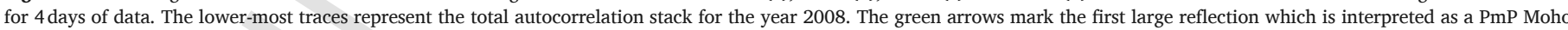

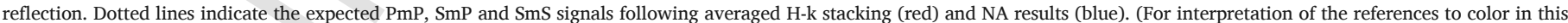
figure legend, the reader is referred to the web version of this article.)

methods suggest a faster arrival. An SmS Moho reflection is not detected for this station.

Regarding to the $\mathrm{Vp} / \mathrm{Vs}$ ratio, the results obtained show values ranging from 1.63 to 1.80 (H-k stacking) and from 1.69 to 1.88 (NA technique). The wide range of values obtained and the complicated RFs observed are, in some cases, due to the complex tectonic settings and the different geological features present at each seismic station (Olivero and Martinioni, 2001; Kraemer, 2003; Lodolo et al., 2003, 2007; Tassone et al., 2005; Menichetti et al., 2008; Peroni et al., 2009; Torres-Carbonnel and Dimieri, 2013). Scattered energy from lateral faults or interfaces can significantly disturb the radial RFs (Abers, 1998). When applying the $\mathrm{H}-\mathrm{k}$ stacking method the presence of multi- 
Table 3

Final results of Moho depth and Vp/Vs values obtained with the H-k stacking method (columns 2nd and 3rd), with the NA inversion (columns 4th and 5th) and with the autocorrelation technique (columns 6 th and 7 th).H-k stacking values are mean values of the eight solutions obtained at each group. $\mathrm{H}_{1}$ and $\mathrm{H}_{2}$ represent the Moho depth calculated using a $\mathrm{Vp}=6.1 \mathrm{~km} / \mathrm{s}$ and the average of $\mathrm{Vp}$ obtained with the NA technique, respectively. With the autocorrelation method we did not considered different groups and therefore we obtained a single value of $\mathrm{H}$ for each station.

\begin{tabular}{lllllll}
\hline & $\mathrm{H}(\mathrm{H}-\mathrm{k})$ & $\begin{array}{l}\mathrm{V}_{\mathrm{p}} / \mathrm{V}_{\mathrm{S}} \\
(\mathrm{H}-\mathrm{k})\end{array}$ & $\mathrm{H}(\mathrm{NA})$ & $\begin{array}{l}\mathrm{V}_{\mathrm{P}} / \mathrm{V}_{\mathrm{S}} \\
(\mathrm{NA})\end{array}$ & $\begin{array}{l}\mathrm{H}_{1} \\
(\mathrm{PCC})\end{array}$ & $\begin{array}{l}\mathrm{H}_{2} \\
(\mathrm{PCC})\end{array}$ \\
\hline $\begin{array}{c}\text { DSPA } \\
\text { group N }\end{array}$ & $23.3 \mathrm{~km}$ & 1.73 & $24.5 \mathrm{~km}$ & 1.88 & $27.5 \mathrm{~km}$ & $27 \mathrm{~km}$ \\
$\begin{array}{c}\text { DSPA } \\
\text { group }\end{array}$ & $24.8 \mathrm{~km}$ & 1.63 & $26 \mathrm{~km}$ & 1.70 & $27.5 \mathrm{~km}$ & $27 \mathrm{~km}$ \\
$\quad$ SW & & & & & & \\
$\begin{array}{c}\text { ELCA } \\
\text { group }\end{array}$ & $28.6 \mathrm{~km}$ & 1.79 & $27.7 \mathrm{~km}$ & 1.88 & $32.6 \mathrm{~km}$ & $33.2 \mathrm{~km}$ \\
$\quad$ SW & & & & & & \\
$\begin{array}{c}\text { TRVA } \\
\text { group N }\end{array}$ & $34.6 \mathrm{~km}$ & 1.65 & $36.6 \mathrm{~km}$ & 1.69 & $33.5 \mathrm{~km}$ & $34.1 \mathrm{~km}$ \\
$\begin{array}{c}\text { TRVA } \\
\text { group }\end{array}$ & $34.8 \mathrm{~km}$ & 1.73 & $39.2 \mathrm{~km}$ & 1.87 & $33.5 \mathrm{~km}$ & $34.1 \mathrm{~km}$ \\
$\quad$ SW & & & & & & \\
$\begin{array}{c}\text { USHA } \\
\text { group N }\end{array}$ & $27.8 \mathrm{~km}$ & 1.80 & $34 \mathrm{~km}$ & 1.81 & $30.5 \mathrm{~km}$ & $32 \mathrm{~km}$ \\
$\begin{array}{l}\text { USHA } \\
\text { group } \\
\text { SW }\end{array}$ & $27.6 \mathrm{~km}$ & 1.66 & $32.3 \mathrm{~km}$ & 1.81 & $30.5 \mathrm{~km}$ & $30.5 \mathrm{~km}$ \\
\hline
\end{tabular}

ples PpPs and PsPs + PpSs is essential, otherwise the Vp/Vs obtained does not represent the average structure. Due to the fact that the reverberations are not as well observed as the Ps conversion at some stations, we have less confidence into the $\mathrm{Vp} / \mathrm{Vs}$ ratio obtained with this technique, particularly for station DSPA.

The shear wave velocity models obtained with the RF inversion indicate that the lowest values of S-wave velocity, in the most superficial layers of the crust, are found at stations DSPA $(\sim 1.75-1.80 \mathrm{~km} /$ s) and ELCA $(\sim 2.4 \mathrm{~km} / \mathrm{s})$. This result correlates well with the presence of Tertiary and upper Cretacic sediments in that area (Olivero and
Martinioni, 2001; Tassone et al., 2005). As mentioned in Section 1, the tectonic setting of TdF is characterized by the MFFS which involves the interaction between the South American and Scotia plates. TRVA and USHA are located to the south of the MFF. The S-wave velocity models obtained at these two stations indicate higher values of seismic velocities and $\mathrm{Vp} / \mathrm{Vs}$ ratio. These S-wave velocity values are consistent with the presence of older geological units composed by lithologies more consolidated to the south of the Island (Menichetti et al., 2008). In the case of USHA (SW-group), the S-wave velocities of the uppermost crust are too high, possibly due to the presence of shallow dipping layers which are not considered in the inversion approach.

The here presented models are sound in the geological context of $\mathrm{TdF}$ and reveal the diverse seismic structure present in the area. The models derived from the NA inversion and the H-k techniques do not change significantly for different parameters or subsidiary data sets showing the robustness of our solutions. The results obtained with different control parameters and initial models converge to similar shear wave velocity models. Furthermore, when applying the inversion for the individual RFs the results show, in most of the cases, similar S-wave velocity models to those obtained when inverting the stacked RFs (see Appendix A). We therefore believe that our models represent closely the local structure beneath the Island. Nevertheless, the installation of more stations and the application of other techniques become necessary to better constrain the crustal structure in TdF.

Supplementary data to this article can be found online at https:// doi.org/10.1016/j.tecto.2018.12.013.

\section{Acknowledgments}

The data used in this study was obtained from scientific projects funded by the National Agency for the Promotion of Science and Technology, Argentina (ANPCyT), the National University of La Plata, Argentina (UNLP) and the National Institute of Oceanography and Experimental Geophysics, Italy (OGS). We would like to thank the staff of the Astronomical Station of Rio Grande (EARG) for the installation and maintenance of seismic stations and Marcelo Moreno from the National Institute of Seismic Prevention (INPRES) for operational support in getting data. Furthermore we are grateful to Larminat and Henninger families for allowing us to install the stations DSPA and ELCA and for providing collaboration with EARG. This work was partially
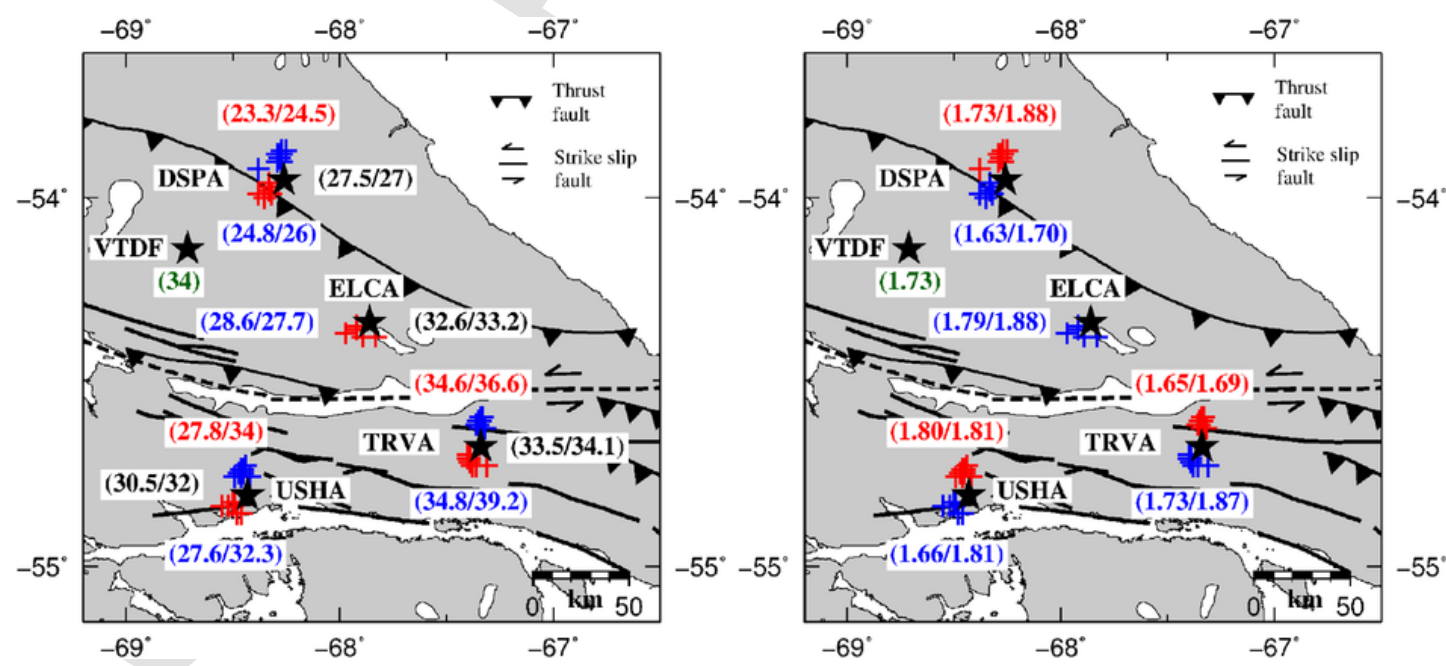

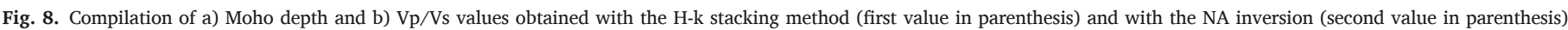

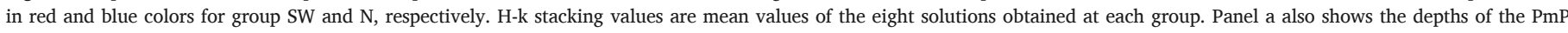

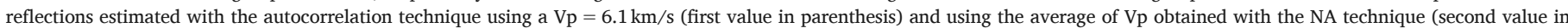

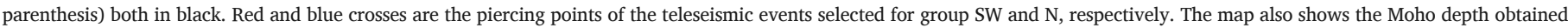
at VTDF station by Lawrence and Wiens (2004). (For interpretation of the references to color in this figure legend, the reader is referred to the web version of this article.) 
supported by a grant from the National Scientific and Technical Research Council (CONICET). Maps were created using the Generic Mapping Tools (GMT) software (Wessel and Smith, 1998). Finally, we would like to thank Alejandro Tassone for helpful comments on the geology. We acknowledge the editor for handling the manuscript and referees for providing us with constructive reviews.

\section{Appendix A.}

The results of the NA inversion of the stacked RFs were presented in Section 3.2.2. Here we show the results for the simultaneous inversion of individual RFs for each group and station (Fig. A.1).
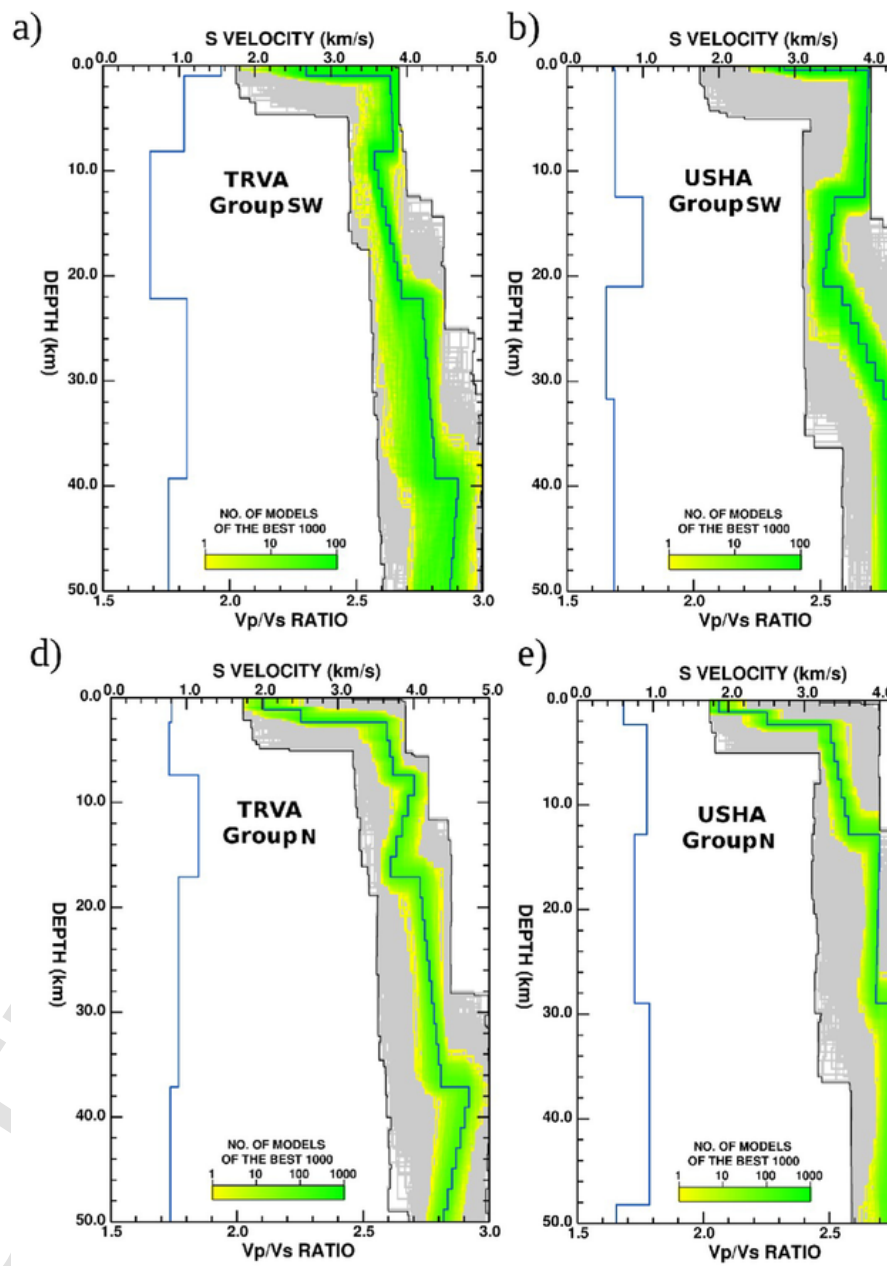

e)
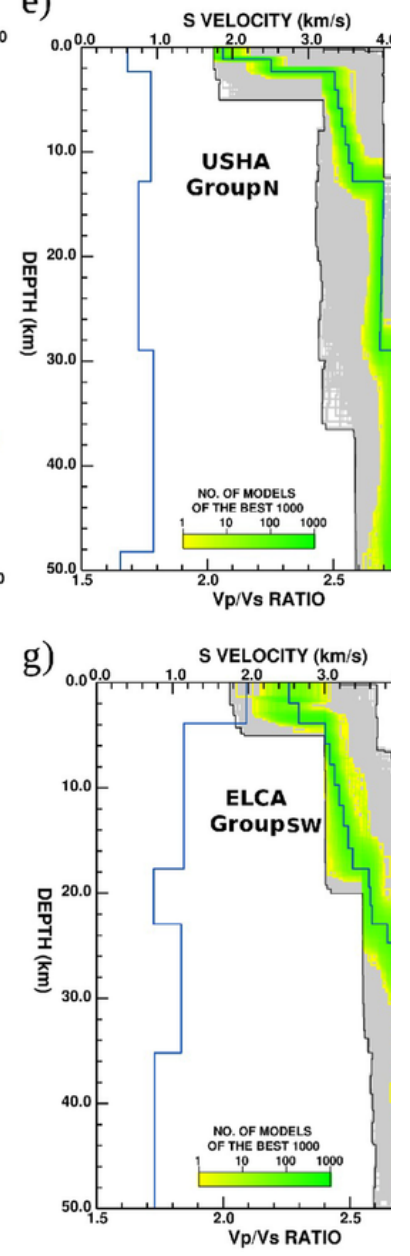

Fig. A.1. NA inversion results for group SW and group $\mathrm{N}$ of station TRVA (a and d), for group SW and group N of station USHA (b and e), for group SW and group $\mathrm{N}$ of station DSPA (c and $\mathrm{f}$ ) and for group SW of station ELCA ( $\mathrm{g}$ ). The full range of models searched in the inversion is shown by the outline of the light grey shading. The green regions show the models with better fit to the observations. The blue lines are the best fitting Vs (right) and $\mathrm{Vp} / \mathrm{Vs}$ (left) ratio model.

The simultaneous inversion was performed using the same initial models and control parameters as those used for the stacked RFs. Fig. A.1 shows the results obtained when applying the NA inversion at all 
the stations considering the contribution of the individual RFs. The green area indicates the density of the 1000 best models, the color being logarithmically proportional to the number of models, as shown by the scale bar. The best data-fitting Vs and $\mathrm{Vp} / \mathrm{Vs}$ ratio are shown in blue.

A comparison of Figs. 6 and A.1 shows a concordance of the main features, as Moho depths and average Vs and Vp/Vs values. Most striking discrepancies are observed at station DSPA where two discontinuities found at $21 \mathrm{~km}$ depth for group SW (Fig. A.1c) and at $19 \mathrm{~km}$ depth for group N (Fig. A.1f) are not visible in the models of the stacked RFs inversions. In the case of station ELCA, a discontinuity at $9 \mathrm{~km}$ depth (Fig. A.1g) was only observed in the models obtained from the inversion of the stacked RFs. These main differences are attributed to the waveform variability of the RFs due to the complex geological settings present in the study area.

\section{References}

Abers, G.A., 1998. Array measurements of phases used in receiver-function calculations: importance of scattering. Bull. Seismol. Soc. Am. 88, 313-318.

Ammirati, J.B., Alvarado, P., Perarnau, M., Saez, M., Monsalvo, G., 2013. Crustal structure of the Central Precordillera of San Juan, Argentina (31S) using teleseismic receiver functions. J. S. Am. Earth Sci. 46, 100-109. https://doi.org/10.1016/j.jsames.2013. 05.007.

Ammon, C.J., 1991. The isolation of receiver effects from teleseismic P waveforms. Bull. Seismol. Soc. Am. 81, 2504-2510.

Ammon, C.J., Zandt, G., 1993. Receiver structure beneath the southern Mojave block, California. Bull. Seismol. Soc. Am. 83, 737-755.

Buffoni, C., 2008. Estudio de sismicidad en la isla de Tierra del Fuego (Unpublished bachelor thesis). Facultad de Ciencias Astronómicas y Geofísicas, Universidad Nacional de La Plata, Argentina, 72.

Buffoni, C., Sabbione, N.C., Connon, G., Hormaechea, J.L., 2009. Hypocentre locations and magnitude determination in Tierra de Fuego and surroundings. Geoacta 34, 75-85.

Caminos, R., Nullo, F., 1979. Descripción geológica de la Hoja 67e. Isla de Los Estados. In: Boletín del Servicio Geológico Nacional (Argentina) 175, pp. 1-175.

Caminos, R., Hall, M.A., Lapido, O., Lizuaín, A., Page, R., Ramos, V., 1981. Reconocimiento geológico de los Andes Fueguinos, territorio Nacional de Tierra del Fuego. In: IIX Congreso Geológico Argentino, Buenos Aires Actas III, pp. 759-786.

Cassidy, J.F., 1992. Numerical experiments in broadband receiver function analysis. Bull. Seismol. Soc. Am. 82, 1453-1474.

Claerbout, J.F., 1968. Synthesis of a layered medium from its acoustic transmission response. Geophysics 33, 264-269.

Dalziel, I.W.D., Dott Jr, R.H., Winn Jr, R.D., Bruhn, R.L., 1975. Tectonic relations of South Georgia Island to the southernmost Andes. Geol. Soc. Am. Bull. 86, 1034-1040.

Del Cogliano, D., Perdomo, R., Hormaechea, J.L., Olivero, E., Strelin, J., Martinioni, D., 2000. GPS detection of movements between SCO and SAM plates in the Argentinean part of Tierra del Fuego Island. In: 31st International Geological Congress, Rio de Janeiro, Brazil.

Febrer, J.M., Plasencia, M.P., Sabbione, N., 2000. Local and regional seismicity from Ushuaia broadband station observations (Tierra del Fuego). In: Terra Antartica 8, pp. 35-40.

Gans, C.R., Beck, S.L., Zandt, G., Gilbert, H., Alvarado, P., Anderson, M., Linkimer, L., 2011. Continental and oceanic crustal structure of the Pampean flat slab region, western Argentina, using receiver function analysis: new high-resolution results. Geophys. J. Int. 186, 45-58.

Ghiglione, M.C., 2003. Estructura y evolución tectónica del cretácico terciario de la Costa Atlántica de Tierra del Fuego (Unpublished PhD thesis). Facultad de Ciencias Exactas y Naturales, Universidad de Buenos Aires, 150.

Gilbert, H., Beck, S., Zandt, G., 2006. Lithospheric and upper mantle structure of Central Chile and Argentina. Geophys. J. Int. 165, 383-398. https://doi.org/10.1111/j. 1365-246X.2006.02867.x.

Goldstein, P., Snoke, A., 2005. SAC availability for the IRIS community. In: Incorporated Institutions for Seismology Data Management Center Electronic Newsletter. http://ds. iris.edu/ds/newsletter/vol7/no1/sac-availability-for-the-iris-community/.

Gorbatov, A., Saygin, E., Kennett, B.L.N., 2013. Crustal properties from seismic station autocorrelograms. Geophys. J. Int. 192 (2), 861-870. https://doi.org/10.1093/gji/ ggs064.

Jaschek, E., Sabbione, N., Sierra, P., 1982. Reubicación de sismos localizados en territorio argentino (1920-1963). In: Vol. XI Geofísica. Publicaciones Observatorio de la Universidad Nacional de La Plata.

Kennett, B.L.N., Saygin, E., Salmon, M., 2015. Stacking autocorrelograms to map Moho depth with high spatial resolution in southeastern Australia. Geophys. Res. Lett. 42, https://doi.org/10.1002/2015GL065345.
Kikuchi, M., Kanamori, H., 1982. Inversion of complex body waves. Bull. Seismol. Soc. Am. 72, 491-506.

Klepeis, K.A., 1994. The Magallanes and Deseado fault zones: major segments of the South American-Scotia transform plate boundary in southernmost South America, Tierra del Fuego. J. Geophys. Res. 99, 22001-22014. https://doi.org/10.1029/94JB01749.

Kraemer, P.E., 2003. Orogenic shortening and the origin of the Patagonian orocline (56 S. Lat). J. S. Am. Earth Sci. 15 (7), 731-748. https://doi.org/10.1016/ S0895-9811(02)00132-3.

Lawrence, J.F., Wiens, D.A., 2004. Combined receiver-function and surface wave phase-velocity inversion using a niching genetic algorithm: application to Patagonia. Bull. Seismol. Soc. Am. 94, 977-987. https://doi.org/10.1785/0120030172.

Ligorría, J.P., Ammon, C.J., 1999. Iterative deconvolution and receiver function estimation. Bull. Seismol. Soc. Am. 89, 1395-1400.

Lodolo, E., Menichetti, M., Bartole, R., Ben-Avraham, Z., Tassone, A., Lippai, H., 2003. Magallanes-Fagnano continental transform fault (Tierra del Fuego, southernmost South America). Tectonics 22 (1076)https://doi.org/10.1029/2003TC001500.

Lodolo, E., Menichetti, M., Zanolla, C., Lippai, H.F., Hormaechea, J.L., Tassone, A., 2007. Gravity map of the Isla Grande de Tierra del Fuego, and morphology of Lago Fagnano. Geol. Acta 5 (4), 0307-0314.

Lomnitz, C., 1970. Major earthquakes and tsunamis in Chile. Geol. Rundsch. 59, 938-960.

Ludwig, W.J., Ewing, J.I., Ewing, M., 1965. Seismic Refraction measurements in the Magellan Straits. J. Geophys. Res. 70, 1855-1876.

Mangino, S.G., Zandt, G., Ammon, C.J., 1993. The receiver structure beneath Mina Nevada. Bull. Seismol. Soc. Am. 83, 542-560.

Mendoza, L., Perdomo, R., Hormaechea, J.L., Del Cogliano, D., Fritsche, M., Richter, A., Dietrich, R., 2011. Present-day crustal deformation along the Magallanes-Fagnano Fault System in Tierra del Fuego from repeated GPS observations. Geophys. J. Int. 184, 1009-1022. https://doi.org/10.1111/j.1365-246X.2010.04912.x.

Mendoza, L., Richter, A., Fritsche, M., Hormaechea, J.L., Perdomo, R., Dietrich, R., 2015. Block modeling of crustal deformation in Tierra del Fuego from GNSS velocities. Tectonophysics 651-652, 58-65. https://doi.org/10.1016/j.tecto.2015.03.013.

Menichetti, M., Lodolo, E., Tassone, A., 2008. Structural geology of the Fuegian Andes and Magallanes fold-and-thrust belt-Tierra del Fuego Island. Geol. Acta 6, 19-42.

Olivero, E.B., Martinioni, D.R., 2001. A review of the geology of the Argentinian Fuegian Andes. J. S. Am. Earth Sci. 14, 175-188. https://doi.org/10.1016/ S0895-9811(01)00016-5.

Oren, C., Nowack, R.L., 2017. Seismic body-wave interferometry using noise autocorrelations for crustal structure. Geophys. J. Int. 208, 321-332. https://doi.org/10.1093/ gji/ggw394.

Perarnau, M., Alvarado, P., Saez, M., 2010. Estimación de la estructura cortical de velocidades sísmicas en el suroeste de la Sierra de Pie de Palo, Provincia de San Juan. Rev. Asoc. Geol. Argent. 64, 473-480.

Peroni, J.I., Tassone, A., Menichetti, M., Cerredo, M.E., 2009. Geophysical modeling and structure of Ushuaia pluton, Fuegian Andes, Argentina. Tectonophysics 476 (3), 436-449. https://doi.org/10.1016/j.tecto.2009.07.016.

Phinney, R.A., 1964. Structure of Earth's crust from spectral behavior of long-period body waves. J. Geophys. Res. 69, 2997-3017. https://doi.org/10.1029/JZ069i014p02997.

Robertson Maurice, S.D., Wiens, D.A., Koper, K.D., Vera, E., 2003. Crustal and upper mantle structure of southernmost South America inferred from regional waveform inversion. J. Geophys. Res. 108 (B1), 2038. https://doi.org/10.1029/2002JB001828.

Romero, P., Schimmel, M., 2018. Mapping the basement of the Ebro Basin in Spain with seismic ambient noise autocorrelations. J. Geophys. Res. Solid Earth 123, https://doi. org/10.1029/2018JB015498.

Ruigrok, E., Campman, X., Wapenaar, K., 2011. Extraction of P-wave reflections from microseisms. Compt. Rendus Geosci. 343 (8-9), 512-525. https://doi.org/10.1016/J. CRTE.2011.02.006.

Ryan, J., Beck, S., Zandt, G., Wagner, L., Minaya, E., Tavera, H., 2016. Central Andean crustal structure from receiver function analysis. Tectonophysics 682, 120-133. https: //doi.org/10.1016/j.tecto.2016.04.048.

Sabbione, N.C., Connon, G., Hormaechea, J.L., Rosa, M.L., 2007. Estudio de sismicidad en la provincia de Tierra del Fuego, Argentina. Geoacta 32, 41-50.

Sambridge, M., 1999. Geophysical inversion with a neighbourhood algorithm I. Searching a parameter space. Geophys. J. Int. 138, 479-494. https://doi.org/10.1046/j. 1365-246X.1999.00876.x.

Schimmel, M., 1999. Phase cross-correlations: design, comparisons and applications. Bull. Seismol. Soc. Am. 89, 1366-1378.

Schimmel, M., Gallart, J., 2007. Frequency-dependent phase coherence for noise suppression in seismic array data. J. Geophys. Res. 112, B04303https://doi.org/10.1029/ 2006JB004680.

Schimmel, M., Paulssen, H., 1997. Noise reduction and detection of weak, coherent signals through phase weighted stacks. Geophys. J. Int. 130, 497-505. https://doi.org/ 10.1111/j.1365-246X.1997.tb05664.x.

Schimmel, M., Stutzmann, E., Ventosa, S., 2018. Low-frequency ambient noise autocorrelations: waveforms and normal modes. Seismol. Res. Lett. https://doi.org/10.1785/ 0220180027. 
Smalley, R., Kendrick, E., Bevis, M.G., Dalziel, I.W.D., Taylor, F., Lauría, E., Barriga, R., Casassa, G., Olivero, E., Piana, E., 2003. Geodetic determination of relative plate motion and crustal deformation across the Scotia-South America plate boundary in eastern Tierra del Fuego. Geochem. Geophys. Geosyst. 4 (1070)https://doi.org/10.1029/ 2002GC000446.

Stockwell, R.G., Mansinha, L., Lowe, R.P., 1996. Localization of the complex spectrum: the S transform. IEEE Trans. Signal Process. 44 (4), 998-1001. https://doi.org/10.1109/ 78.492555 .

Tassone, A., Lippai, H., Lodolo, E., Menichetti, M., Comba, A., Hormaechea, J.L., Vilas, J.F., 2005. A geological and geophysical crustal section across the Magallanes-Fagnano fault in Tierra del Fuego and associated asymmetric basins formation. J. S. Am. Earth Sci. 19, 99-109. https://doi.org/10.1016/j.jsames.2004.12.003.

Taylor, D.G., Rost, S., Houseman, G., 2016. Crustal imaging across the North Anatolian Fault Zone from the auto-correlation of ambient seismic noise. Geophys. Res. Lett. 43 (6), 2502-2509. https://doi.org/10.1002/2016GL067715.

Tibuleac, I.M., von Seggern, D., 2012. Crust-mantle boundary reflectors in Nevada from ambient seismic noise autocorrelations. Geophys. J. Int. 189 (1), 493-500. https:// doi.org/10.1111/j.1365-246X.2011.05336.x.
Torres-Carbonnel, P.J., Dimieri, L.V., 2013. Cenozoic contractional tectonics in the Fuegian Andes, southernmost South America: a model for the transference of orogenic shortening to the foreland. Geol. Acta 11 (3).

Wapenaar, K., Thorbecke, J., Draganov, D., 2004. Relations between reflection and transmission responses of three-dimensional inhomogeneous media. Geophys. J. Int. 156 (2), 179-194.

Wessel, P., Smith, W.H.F., 1998. New, improved version of the Generic Mapping Tools released. EOS Trans. Am. Geophys. Union 79, 579.

Zhan, Z., Ni, S., Helmberger, D.V., Clayton, R.V., 2010. Retrieval of Moho-reflected shear wave arrivals from ambient seismic noise. Geophys. J. Int. 182, 408-420. https://doi. org/10.1111/j.1365-246X.2010.04625.x.

Zhu, L., Kanamori, H., 2000. Moho depth variation in southern California from teleseismic receiver functions. J. Geophys. Res. 105, 2969-2980. https://doi.org/10.1029/ 1999JB900322. 
RFs without a clear Ps conversion from the Moho and without a first positive pulse at $0 \mathrm{~s}$ (direct P-wave arrival) were removed from the following analysis. After data processing and RF selection (see previous section) we retain a total of $106 \mathrm{RFs}$ (Table 1 ). The recovery percentage of the radial waveform was evaluated by the RMS (Root Mean Square) between the original radial waveform and the convolution between the radial $\mathrm{RF}$ with the original vertical component. All the selected $\mathrm{RF}$ were visually inspected controlling the coherence of the waveform and the stability. Approximately, the $86 \%$ of the selected RFs have a correlation or misfit value $>70 \%$ (Fig. S1 in the Supplementary material section). RFs with a misfit $>60 \%$ still contributed positively to one or the other reverberation and were therefore not retained from the analysis.
A visual inspection of the RFs from Fig. 3 shows a certain degree of waveform complexity. Simple waveforms cannot be expected due to the complex geological settings. The map in Fig. 1 shows that the stations are all located close to fault systems at the margins of different tectonic units. Nevertheless, the RFs obtained show that the energy is mostly concentrated in their radial components (Fig. S2 in the Supplementary material section) and not in the transverse ones which gives us the confidence that the lateral homogeneous model assumption is still a valid approximation for our data. In all RF sections we can identify the Ps conversion from the Moho between 3 and $4.5 \mathrm{~s}$. The PpPs and PpSs + PsPs reverberations are difficult to identify in some groups due to the waveform complexity of our RF data. 